\title{
Lógica relacional del Estado: Revisitando el aporte teórico de Nicos Poulantzas en Estado, Poder y Socialismo
}

Javier Fernández ${ }^{1}$

\section{Aporte de estudiante}

Posgrado

Resumen: Durante mucho tiempo, el estudio del Estado ha estado signado por una comprensión monolítica, toda vez que se ha entendido o como la única posibilidad para evitar la batalla de todos contra todos, la expresión suprema de la sociedad o un acuerdo de una clase para la mera opresión de otra. Bajo esta premisa, es que Nicos Poulantzas desarrollará una propuesta crítica en la concepción y abordaje de la arquitectura estatal, comprendiéndola como un espacio de constante disputa y cristalización del conflicto de clases, apuntando a entenderlo como a un todo complejo que nunca logra pertenecer por entero a un sector. Dichas observaciones revisten una importancia trascendental dado que, con ello, quienes aspiren a comprender la institucionalidad desde las Ciencias Sociales, encontrarán una propuesta compleja para el estudio del Estado. En esta lógica es que el presente trabajo pretende ser una revisión de Estado, Poder y Socialismo de Poulantzas, considerando que este texto guarda un aporte teórico fundamental para el estudio politológico. Abocándonos a revisar algunos planteamientos, apuntamos a aportar algunas orientaciones conceptuales del autor greco-francés a fin de que puedan servir para profundizar en un proyecto teórico de suma relevancia en los tiempos que la desafección política y las luchas por el Estado están más presentes que nunca.

\section{Introducción}

Amado por unos, odiados por otros, el Estado cumple un rol preponderante en el estudio politológico de las sociedades modernas. A los célebres clásicos del pensamiento como Hobbes, Maquiavelo o Hegel, se le sumó en el siglo XIX los importantes aportes de Karl Marx y sus posteriores herederos bajo la premisa superestructural. Sin embargo, no sería hasta la llegada Gramsci que los marxistas pasarían a observarlo desde una problematización compleja más allá de un simple "órgano conciliador de clases" (Lenin, 2007). En esta tarea, es posiblemente Nicos Poulantzas uno de los marxistas que más esfuerzos hizo para analizar la lógica del Estado contemporáneo de forma compleja.

\footnotetext{
${ }^{1}$ Tesista de Magíster en Ciencia Política por la Universidad de Chile. Becario ANID Magíster Nacional 2021. Se ha desempeñado como ayudante de cátedra en pregrado y actualmente trabaja como ayudante de investigación en proyectos Fondecyt.

Correo electrónico: jfernandezb92@gmail.com
} 
Es por lo anteriormente dicho, que el presente trabajo pretenderá revisar de manera sucinta el pensamiento de Nicos Poulantzas en torno a Estado, Poder y Socialismo, y cómo éste, configura un aporte a las Ciencias Sociales al comprender de forma multidimensional el Estado capitalista moderno.

\section{Ni cosa ni sujeto: relación y autonomía relativa}

Abordar el pensamiento de Nicos Poulantzas lleva, obligatoriamente, a referirse a los planteamientos que ostentarían -durante mucho tiempo- los partidos comunistas de la III Internacional. Basados en un canon dogmático, heredado de los tardíos textos de Marx (Anderson, 2011), no fueron pocos los que sucumbieron al eslogan -devenido cliché- en considerar al Estado como nada más que "una junta que administra los negocios comunes de toda la clase burguesa" (Marx, 2015, p. 119). Este mismo pensamiento se instaló en la Internacional mediante la teorización de Lenin (2007) quien, en El Estado y la Revolución, lo inscribiría como un órgano conciliador de clases y que, aun cuando fundamental para la construcción del socialismo, no había que olvidar su carácter eminentemente contrario con los intereses populares.

Al igual como hiciera Gramsci anteriormente, Poulantzas comprendió lo fundamental que era el entendimiento del Estado más allá de una ideación Superestructural eminentemente subsumido en la Infraestructura. Dice el mismo autor que:

una teoría del Estado capitalista no puede construir su objeto refiriéndose solamente a las relaciones de producción sin que la lucha de clases en las formaciones sociales, intervengan más que como simple factor de variación o de concretización de este Estado, tipo ideal, en tal o cual Estado concreto. (Poulantzas, 2005, p. 147)

Junto con ello, dirá el greco-francés, durante mucho tiempo la teoría ha caído en "las trivialidades dogmáticas del siguiente género: todo Estado es un Estado de clase (...) y todo Estado capitalista en particular es una dictadura de la burguesía" (Poulantzas, 2005. p. 149). Si todo esto se configura como un problema para el avance de las luchas populares ¿dónde reviste la posibilidad de la superación de este embrollo?

Para esto, sería fundamental considerar que las disputas del Estado -signadas por la lucha de clases- no se configuran en una articulación de una clase dominante, sino de clases dominantes que se disputarían el control de éste.

Para Poulantzas, es básico comprender la multitud de grupos que convergen en la conformación de un bloque histórico -parafraseando a Gramsci- y que, en este mismo sentido, dan dirección a las clases dominadas o grupos subalternos. Sin embargo, sería equivocado considerar a estos como un conjunto homogeneo y que se entiende con intereses idénticos. 
Por el contrario, encuentran una serie de contradicciones, conformando alianzas, a fin de asegurarse la dirección y prevalecer en sus propios intereses.

Si esto cobra sentido, dice el autor, será necesario superar el entendimiento poco riguroso del Estado como "Cosa" y como "Sujeto" y observarlo como una "Relación". Aun cuando, advierte, no es una relación pura y simple, sino como "una condensación material y específica de una relación de fuerzas entre clases y facciones de clases" (Poulantzas, 2005, p. 155). Entenderlo así lleva a la comprensión de que, por un lado, no sería una "CosaInstrumento" manipulado por una clase homogénea, pasivo o neutro y, por el otro, como "Sujeto" con una autonomía total, desprovista de la misma relacionalidad de la lucha de clases. Al ver al Estado como "Cosa" las clases absorverían al Estado, mientras que como "Sujeto" sería éste el que absorvería a las clases, todo en un juego de suma cero.

Observada así esta "Relación" inscrita en el Estado, permitiría notar cómo la clase dominante, y sus facciones, establecen estrategias a fin de generar elementos que le permitan direccionar en pos de intereses, formando incluso alianzas con otros sectores subalternos ascendentes, como lo es la pequeña burguesía. Esto, porque si las clases no son iguales, tampoco son los intereses: el desarrollo monopolista del capital entra en contradicción con las facciones no-monopolistas que conciben la dirección estatal de un cierto modo que muchas veces tensiona la misma relación del bloque en el poder².

Lo anterior, en palabras del mismo autor, conlleva a "abandonar así, definitivamente, una visión del Estado como dispositivo unitario, de arriba-abajo, fundado en una distribución jerárquica homogénea de los centro de poder, en escalonamiento uniforme" (Poulantzas, 2005, p.160). Sin embargo, esta mirada "relacional" observa que el Estado tiene una cierta autonomía para operar que, si bien no es total, sí es relativa, ya que cristaliza las contradicciones del bloque dominante. La posibilidad estratégica de concretizar proyectos contradictorios del mismo, viabiliza a una faccion de clase llevar su proyecto a puerto combatiendo y coordinando todo al mismo tiempo con las otras facciones. De ahí su autonomía relativa: ya que es un resultado de lo que sucede en el Estado, a su vez con cierta autonomía de los demás grupos del mismo (tribunales o parlamento, por ejemplo).

Una advertencia que hace el autor es la concepción de que estas mismas contradicciones alojarían la obligatoriedad de distinguir entre el poder real y el poder formal. Una especificidad que muchos años después recordaría el líder de PODEMOS, Pablo Iglesias, que lo relataría como "tener el gobierno no es lo mismo que tener el Poder" (Iglesias,

\footnotetext{
${ }^{2}$ Expresión de esto se encuentra, por ejemplo, en los procesos acaecidos en Chile desde octubre de 2019: las posibilidades abiertas con apoyos otorgados por facciones más "sociales" del bloque en el poder entran en conflicto con las más "conservadoras" evidenciando que los planteamientos de Poulantzas cobran absoluta actualidad en tanto no se actúa, en ningún momento, como un bloque homogéneo.
} 
2014, p. 171). O, en palabras del mismo Poulantzas, "una ocupación del gobierno por la izquierda, no significa, ni forzosa ni automáticamente, que la izquierda controle los aparatos del Estado, y ni siquiera alguno de ellos" (Poulantzas, 2005, p.166) ${ }^{3}$.

Es interesente notar que, aun cuando las facciones de la clase dominante entran en contradicciones y disputas entre ellas, eso no las exime de las conflagraciones con las clases populares. Para ello, nos dice el sociólogo, ciertos segmentos de esta clase dominante entra en alianzas también con clases subalternas, a fin de generar los concensos propios de mantenimiento en el Poder, muy específicamente, con la pequeña burguesía a fin de frenar avances.

La capacidad de los sectores dominantes de entrar en coordinación a su vez no sólo con clases subalternas como la pequeña burguesía, sino también con facciones del capital se ve, en el pensamiento del greco-francés, en las mismas expresiones del Estado que se desarrolla en distintos lugares de Europa. Un ejemplo de esto puede hallarse en lo relatado por Hall y Soskice (2006) en las Economías de Mercado Coordinadas. La capacidad de poder hallarse en una planificación mancomunada, pero a la vez que permite entender las alianzas generadas entre las facciones, materializa precisamente la coordinación que toman con sectores del capital -no con todo, sino que con facciones-, desarrollando desde el Estado un programa que permite observar elementos que funcionan en concomitancia. Este desarrollo, en la observación de Poulantzas, obedecería al intento de aumentar la tasa de ganancia, aun cuando -no siempre continua en el tiempo-, dependerá mucho de las coyunturas, así como también la capacidad de alianzas con otros sectores.

\section{Conclusión}

Lo relatado en este aporte, fue un intento de revisar suscitamente la propuesta teórica de Nicos Poulantzas expresada en Estado, Poder y Socialismo. De manera sintética, podemos observar que el proyecto del greco-francés apunta a superar las lógicas monolíticas del Estado, diversificando su estudio para las Ciencias Sociales y los proyectos de emancipación. Tarea que pese a los años aún sigue sumamente vigente.

Por un lado, es de suma importancia comprender que por fuera del Estado "CosaInstrumento" y "Sujeto", este estaría inmerso en una "Relación", comprendiendo que nunca la clase dominante entra como un corpus unificado al poder. Por el otro lado, las lógicas relacionales obligarían a observar la "autonomía relativa" con la que opera el Estado, como espacio por antonomasia de la expresión conflagrante de clases y sus proyectos. Con la

\footnotetext{
${ }^{3}$ Otro ejemplo trágico ocurre en nuestra región al revisarse los golpes de Estado acaecidos no sólo en la segunda mitad del siglo XX, sino con expresiones de "Neogolpes" contra gobiernos progresistas de este siglo (Leyva, 2020).
} 
desafección política y la entrada de nuevos actores habrá que atender la relacionalidad que operaría en el Estado de aquí en más por parte de los sectores subalternos.

\section{Referencias}

Anderson, P. (2011). Consideraciones sobre el marxismo occidental. Siglo XXI.

Hall, P. H. y Soskice, D. (2006). A propósito de los capitalismos contemporáneos:

Variedades de capitalismo: Algunos aspectos fundamentales. Desarrollo Económico, 45(180), 573-590.

Iglesias, P. (2014). Disputar la Democracia: política para tiempos de crisis. Akal.

Lenin, V. I. (2007). El Estado y la revolución. Longseller.

Leyva, F. (2020). La cláusula democrática de la OEA: el reto de defender (y definir) la democracia en América Latina. Contextualizaciones Latinoamericanas, 1(23), 103-113.

Marx, K. (2015). Antología. (H. Tarcus, Ed.) Siglo XXI.

Poulantzas, N. (2005). Estado, Poder y Socialismo. Siglo XXI. 